\title{
Performance on a four-choice search task following septal lesions in the rat
}

\author{
M. A. MILLER, W. C. INNES, and L. J. ENLOE \\ Idaho State University, Pocatello, Idaho 83209
}

\begin{abstract}
Normal rats and rats with lesions in the septum were run on a four-choice search task for 12 trials a day for 12 days. Results showed that there were significant differences in acquisition of a position preference and number of errors. Additionally, lesioned subjects made significantly more vicarious choices than did sham-operated controls. The significance of these findings for learning deficits and spatial cue utilization were discussed.
\end{abstract}

Following septal lesions, rats exhibit a marked tendency to overrespond on operant tasks, active and passive avoidance, and measures of consummatory responding. While these effects have variously been explained as indicating a lack of somatomotor inhibition, learning deficits, and alterations in reactivity, recent researchers have hypothesized that lesions of the septum reduce an animal's ability to utilize spatial and kinesthetic information (Dalland, 1974; Ellen, Wilson, \& Powell, 1964; Thomas, 1972).

This hypothesis was first put forward by Ellen et al. (1964), who noted that the DRL deficit in septal preparations was related to an increased tendency to respond early in the delay interval. As normal or sham-operated subjects typically display a unimodal response pattern, with higher responses late in the delay interval, and as subjects with septal lesions failed to improve with extended practice, Ellen et al. concluded that the septal deficit reflected a relative inability to utilize response-produced cues. Following up on this hypothesis, Ellen and Butter (1969) reported that, although response-produced cues are not sufficient to produce significant improvement, when external cues are added, septal preparations can perform the DRL task as well as do controls.

The use of response-produced cues in performance of a spontaneous alternation task is also known to be affected by septal lesions. When tested in a T-maze, lesioned subjects failed to spontaneously alternate (Douglas \& Raphelson, 1966), an effect which has been attributed to medial septal damage (Clody \& Carlton, 1969). Furthermore, both Dalland (1974) and Thomas (1972) have reported that this effect is related to a marked tendency to perseverate to external cues (visual and olfactory) and that, unlike controls, septal preparations do not utilize spatial information.

In contrast, while septal lesions do produce a dramatic deficit on spatial alternation and spatial reversal tasks (Schwartzbaum \& Donovick, 1968;
Singh, 1973; Srebro and Divac, 1972), the deficit on these tasks can be directly related to an overuse of positional or spatial information. Typically, the reversal deficit following septal lesions is produced by a strong perseverative tendency: that is, lesioned subjects take longer to shift away from a previously reinforced positional response, and develop strong positional preferences that are broken only with repeated reversal training. Additionally, strong positional preferences in rats with septal lesions have been reported to interfere with the acquisition of a negatively reinforced brightness discrimination (Duncan \& Duncan, 1971) and to facilitate learning of a difficult T-maze discrimination (Gomer \& Goldstein, 1974).

While these studies seem to indicate that septal preparations can and do use spatial information in the form of positional preferences, such tendencies might well be influenced by training. In all of the spontaneous alternation tasks, animals were tested on relatively few trials per day, and for relatively few days. In contrast, spatial alternation and reversal tasks require extended practice both within and over days. Although Duncan and Duncan (1971) reported that their experimental subjects developed a strong positional preference in only one trial, it would be more reasonable to assume that it would develop over time and training, especially in light of evidence that other deficits associated with septal lesions are specifically related to postoperative training (Butters \& Rosvold, 1968; Fried, 1969).

In the current study, this hypothesis was examined, using a four-choice spatial search task. As in spontaneous alternation tests, all alleys were reinforced; however, extended practice was given, such that its effects on the development of position preferences might be assessed. Secondly, the effect of spatial preferences on errors and latency measures was examined, as studies by Srebro (1974) and Srebro and Divac (1972) indicate that operated subjects 
display more errors and vicarious approaches on spatial tasks when relevant visual cues are unavailable.

\section{METHOD}

\section{Subjects}

The subjects used in this study were 16 male hooded LongEvans rats weighing between 275 and $350 \mathrm{~g}$ at the start of the experiment. All rats were individually housed in suspended (Wahman) cages, and all were maintained on a 12-h light-dark cycle. Prior to Day 7 postop, ad-lib food and water were available.

\section{Apparatus}

The test apparatus used was the four-choice alley maze shown in Figure 1. It consisted of a startbox $(15.2 \mathrm{~cm}$ wide) with a guillotine door opening on to four goalboxes (each measuring $26.7 \mathrm{~cm}$ long, $12.4 \mathrm{~cm}$ wide). Each goalbox contained a watch dish as a feeder and had a black line marking the half way point in the alley. The distance from the startbox to the goalboxes measured $25.4 \mathrm{~cm}$. The subject had to run through a swinging door to enter the goalbox. The floor of the startbox and entry way was a grid made of $3 / 16$ in. brass rods placed $1 / 2$-in apart, while the floor in the goalboxes was solid wood. The apparatus and doors were painted with gray enamel and the top was clear Plexiglas. A 10-W light illuminated the room.

\section{Surgery}

Prior to the initiation of testing, the subjects were randomly assigned to one of two experimental groups. Subjects in Group N were subjected to sham-operation procedures, and subjects in Group $S$ received septal lesions.

All surgery was performed under a combination of sodium pentobarbital and methoxyfluoride anesthesia. Each subject received IP injections of $.15 \mathrm{cc}$ of $50-\mathrm{mg} / \mathrm{cc}$ sodium pentobarbital and $.15 \mathrm{cc}$ of atropine sulfate. Methoxyflouride was administered as a gaseous supplement.

Rats given septal lesions were centered in the ear bars, a midline incision was made, and a hole was drilled through the skull with a trephine. A stainless steel needle electrode, insulated except for $1 \mathrm{~mm}$ at the tip, was stereotaxically lowered into the brain, and a lesion was produced by a radio-frequency Grass lesion maker. A ground was established by means of an anal electrode. The stereotaxic coordinates used were from the deGroot (1959) atlas and were $+7.8 \mathrm{AP}, \pm .5 \mathrm{~L}$, and $+.9 \mathrm{DV}$. Sham procedures consisted of placing the rat in the ear bars, making the midline incision, drilling the hole in the skull, and stitching up the incision.

Following surgery, all animals were returned to their home cages, food-deprived for $6 \mathrm{~h}$, and then returned to ad-lib food and water.

\section{Training Procedures}

All animals were allowed 2 days of recovery, followed by 5 days of adaptation to handling procedures and 4 days of adaptation to the apparatus. During handling, the subjects were removed from their cages, stroked longitudinally on the back for 3 to $5 \mathrm{~min}$, then returned to their home cages. Adaptation to the apparatus consisted of allowing the subjects to explore the apparatus for $20 \mathrm{~min}$ a day for 4 days. During this time, no swinging doors were present and each goalbox contained approximately 30 45-mg Noyes pellets. Twenty-three-hour food-deprivation procedures were initiated on Day 7 postop.

On the day after completion of adaptation, pretraining techniques were begun. During this time, a discrete trial procedure was initiated: each subject was placed in the startbox, and then was allowed to remain in the apparatus until it had eaten food out of each goalbox, or until $5 \mathrm{~min}$ had elapsed. Food reinforcement

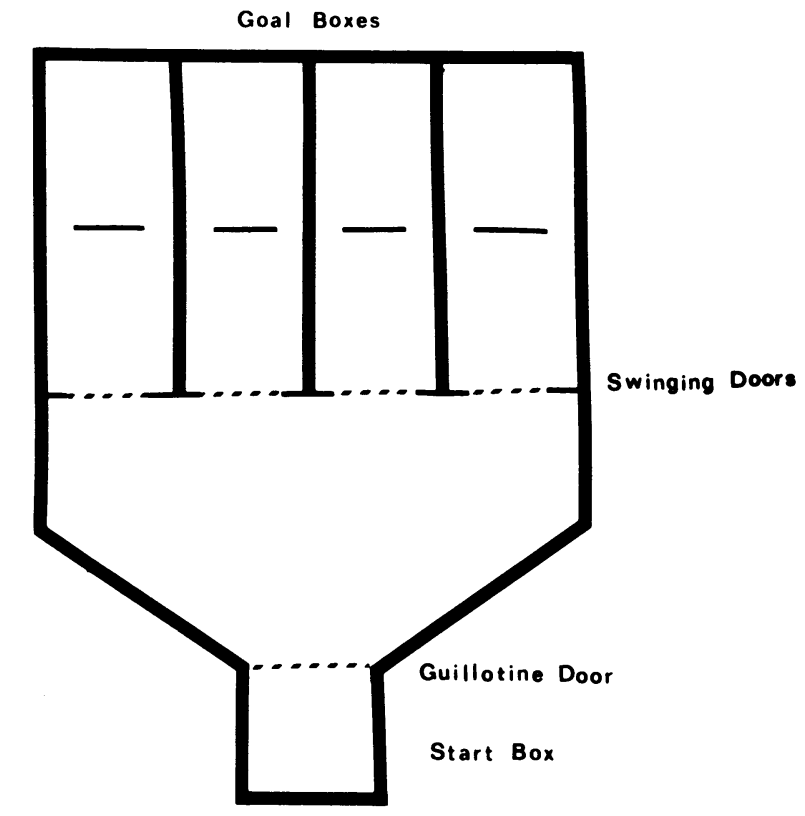

Figure 1. Test Apparatus.

consisted of priming each goalbox with one 45-mg Noyes peliet. Five trials a day were run, and each subject received three phases of pretraining. During Phase 1, half-length swinging door were placed into the opening of each goalbox; during Phase 2. threequarter-length doors were used; and during Phase 3, full-length doors were placed into the apparatus. Each rat was run on each phase until he had completed 2 consecutive days of running in which no more than 3 min were required to obtain all food on any given trial.

When each subject had met criterion on Phase 3 of pretraining, he was advanced to search training/testing. Search trials were run for 12 trials a day for 12 consecutive days. During this time, procedures were similar to those during pretraining. The subject was placed in the startbox, the guillotine door raised, and the time from raising the door until the subject had obtained all reinforcement was recorded. Additionally, the experimenter recorded the location of each goalbox entered (in sequence) and two types of error. Error A consisted of pushing open a swinging door but not entering the alley, while Error B consisted of placing the forepaws beyond the black line in an incorrect alley, that is, an alley from which the food had previously been retrieved. Each trial was considered complete when the subject either obtained all reinforcement or failed to obtain them within $3 \mathrm{~min}$. Failure to complete the task resulted in termination of the trial, and these trials were rerun. All animals were run in groups of six, such that the intertrial interval averaged around $4-5 \mathrm{~min}$.

\section{Histological Procedures}

On the day following completion of the experimental conditions, all lesioned animals were anesthetized with $1.0 \mathrm{cc}$ of sodium pentobarbital and then intracardially perfused with a $0.9 \%$ saline followed by $10 \%$ Formalin. The brains were frozen and 40 -micra sections were taken. The sections were mounted on slides, stained with thionine, and examined for size and extent of the lesions.

\section{RESULTS}

\section{Histological Results}

As expected, septal lesions were large and relative- 


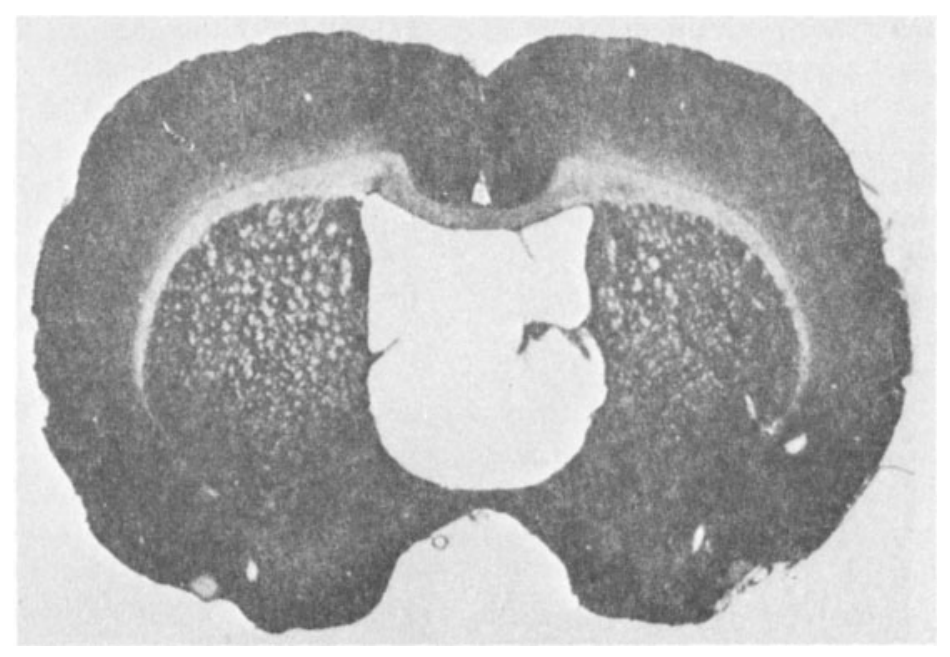

Figure 2. Typical septal lesion.

ly consistent with the section shown in Figure 2. They extended from the genu of the corpus callosum anteriorly to about deGroot level 6.8 posteriorly. Structures involved were the medial paraolfactory area, the nucleus accumbens septi, the lateral and medial septal nuclei, the diagonal bands, the anterior commissure, the columns of the fornix, the triangular septum, the nucleus dentalis fimbrialis, the nucleus interstitialis stria terminalis. The caudate nucleus and the hippocampus were slightly invaded in most subjects. The nucleus paratenialis, nucleus ventricularis, and stria medullaris thalami were involved in about $50 \%$ of the subjects, and finally the preoptic nucleus of the hypothalamus and the corpus callosum were invaded in less than $25 \%$ and $33 \%$, respectively. Lesion size and variability were observed to have no apparent effect on behavioral measures.

\section{Behavioral Results}

Pretraining data were analyzed by means of $t$ tests, and it was found that, though behavioral criteria were used to progress subjects through training, there were no significant differences in the number of pretraining trials between groups. Results for the testing conditions were compared between groups using a 2 by 12 analysis of variance for repeated measures. All effects reported as significant were beyond the .05 confidence level.

Behavior was first assessed via computation of

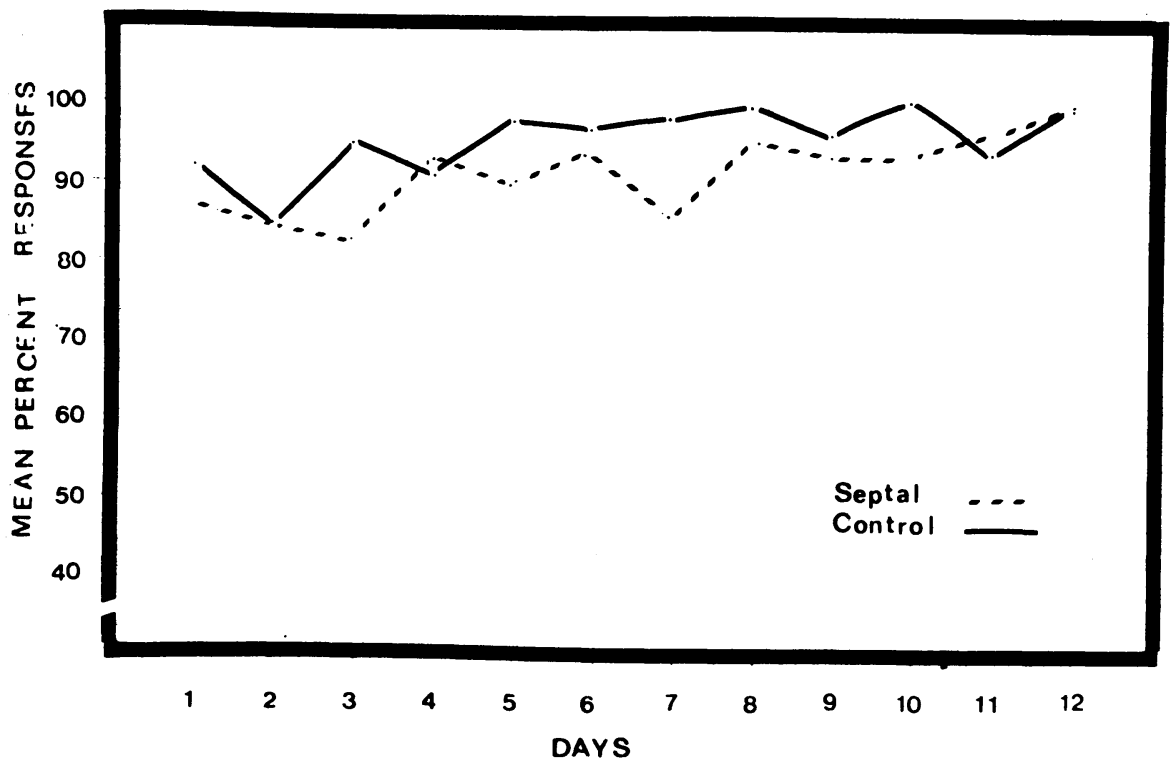

Figure 3. Mean Daily Position Preference. 
each subject's initial position preference. For each day, the percentage of first choices directed at each goalbox by each subject was computed, and the highest percentage then became that subject's score for that day. As shown in Figure 3, both groups of rats demonstrated strong position preferences, with between $80 \%$ and $100 \%$ of the responses being directed to the preferred box.

Throughout testing sessions, preference scores for both groups remained high, but differences between groups were present, indicating that septal lesions do have a marked effect on the use of spatial information. While preference scores for both groups were high, the preference behavior of the control subjects was significantly higher than that of the lesioned animals $[F(1,168)=6.64, p<.01]$, with the greatest difference occurring on Test Days 5-10. Additionally, while scores for the normal group stabilized after the first 4 days, scores for Group $S$ continued to vary for around 8 days. Although there was a significant Days effect, indicating a significant improvement for both groups over time $[F(11,168)=1.93$, $\mathrm{p}<.05]$, there was no significant Groups by Days interaction $[\mathrm{F}(11,168)=.72]$.

In combination with the finding that lesioned animals were less likely to choose the same goalbox first on every trial, it was also found that they were significantly more likely to make a higher number of choices on each day $[F(1,168)=11.5, p<.05]$. The average number of choices for the 12 daily trials, illustrated in Figure 4, indicates that on the first day, control subjects were making 66 responses per day, or 5.5 choices per trial, whereas lesioned animals were making 78 responses, or 6.5 choices per trial. While the two groups showed significant improvement over Days $[F(11,168)=4.61, p<.05]$,
Group S never attained the level of performance exhibited by the controls and throughout the 12 test days continued to make significantly more choices. At their best (Days 5 and 7), they made 55 responses per day, only 48 of which were reinforced. In contrast, after Day 3, the control subjects never made more than 55 choices, and on Day 11 made only 49 (98\% reinforced). Finally, the analysis revealed no significant Groups by Days interaction $[F(11,168)$ $=.44]$.

When the choices are broken down into Type A and Type B errors, as in Figures 5 and 6, it can be seen that the tendency for septal preparations to make more choices than did controls is related to a definite tendency to make partial or anticipatory entries into the goalbox (Type A errors). Throughout testing, experimental subjects made nearly three times as many Type A errors as did the control subjects, leading to a significant Groups effect $[F(1,168)=33.8, p<.01]$. As was found in the analysis of choices, the greatest number of errors was made on Day 1, and significant improvement was exhibited during the first 4 days of testing $[F(11,168)$ $=3.36, p<.011$. Furthermore, as the occurrence of Type A errors was consistently low in the control group, while Group S demonstrated improvement with time, there was a significant Groups by Days interaction $[F(11,168)=2.28, p<.01]$ for the Type A measure.

In contrast, control animals were much more likely to make a Type B error-full entry into a nonreinforced goalbox. In this case, the analysis revealed, again, a significant difference in groups $[F(1,168)$ $=21.6, \mathrm{p}<.011$. There were, moreover, significant differences related to a decrease in Type B errors over testing sessions $[\mathrm{F}(11,168)=11.1, \mathrm{p}<.01]$ and

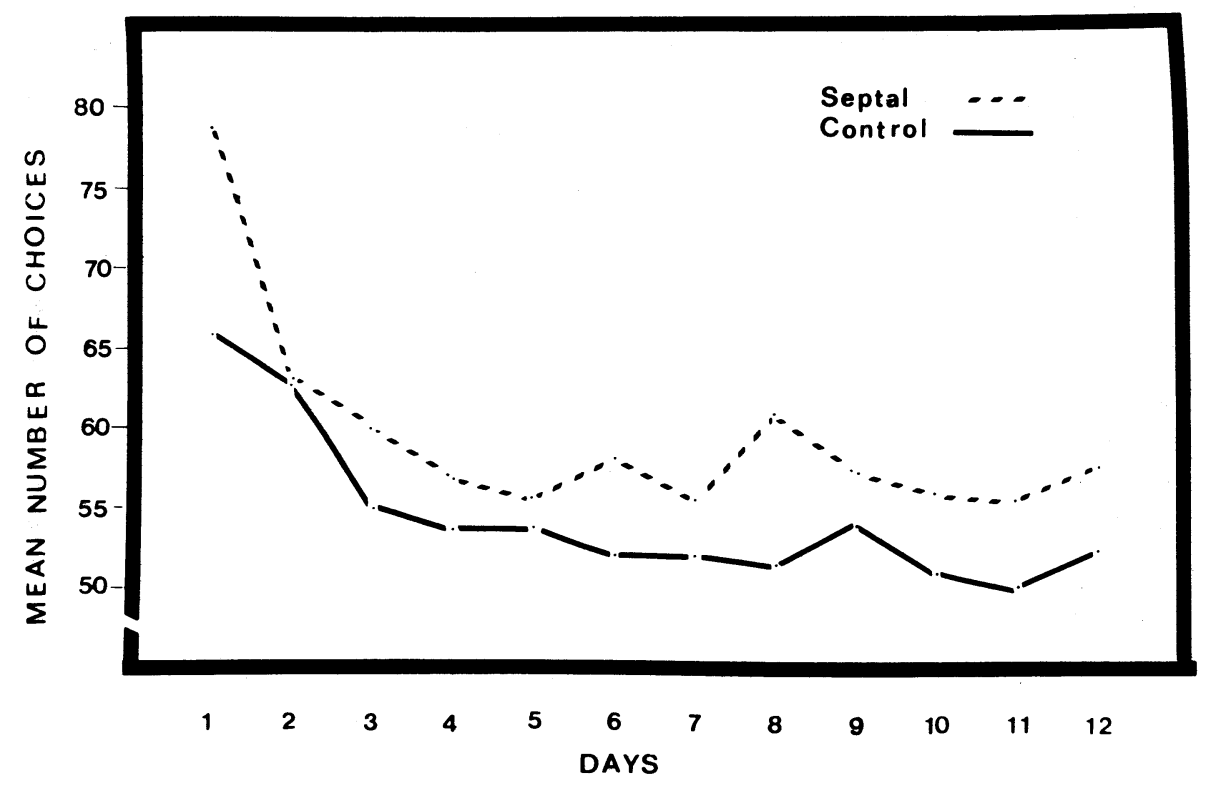

Figure 4. Mean number of choices over days. 


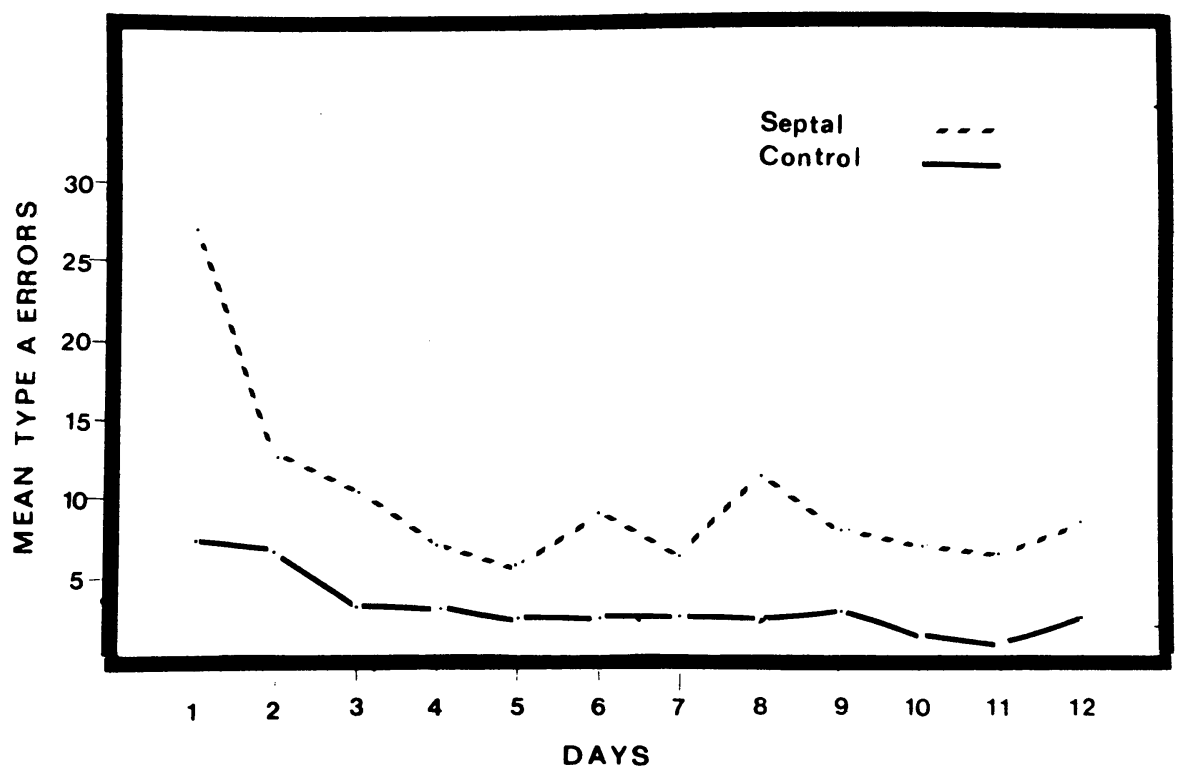

Figure 5. Mean Type A errors: Partial entry into the goalbox.

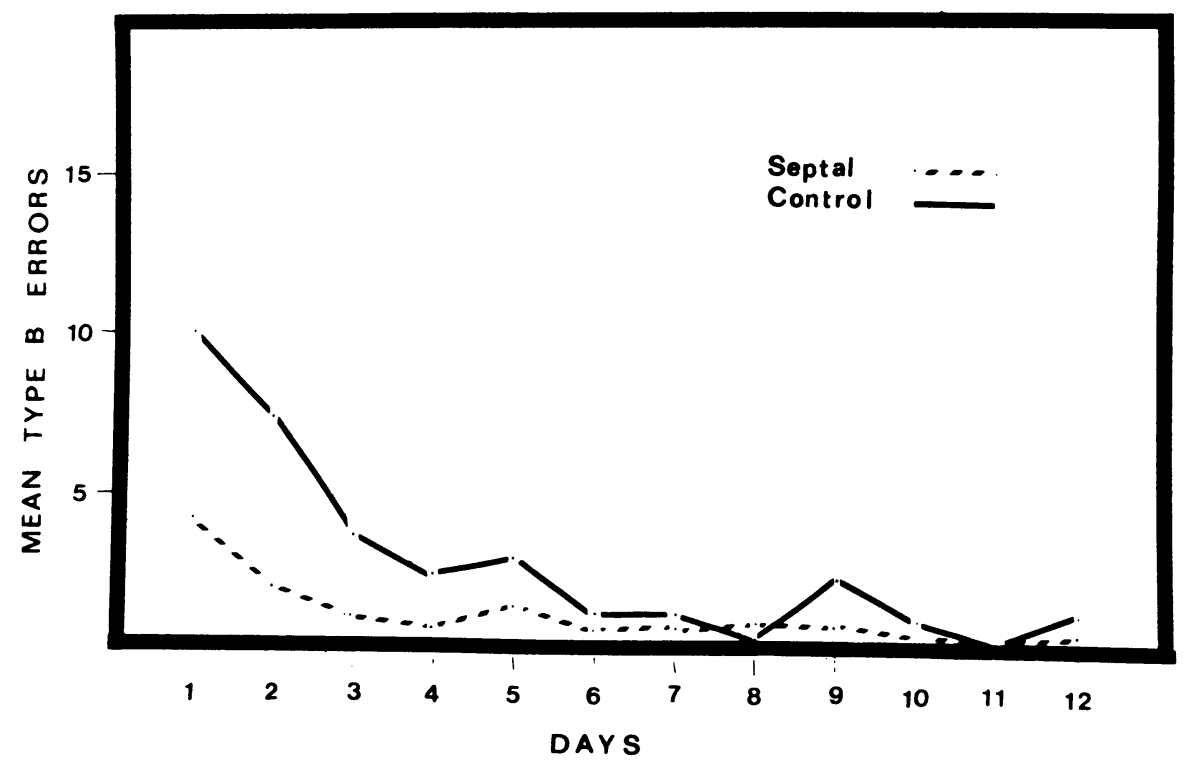

Figure 6. Mean Type B errors: Full entry into the goalbox.

a significant Groups by Days interaction $[\mathrm{F}(11,168)$ $=2.66, \mathrm{p}<.01]$.

Results of the final measure, latency to complete the task, are illustrated in Figure 7. Analysis of these scores indicated no differences between groups. Both groups started out with extremely long latencies on Day 1, which decreased rapidly through the first 3-4 days. There was, however, no significant Days effect $[F(11,168)=1.29]$, probably due to the large within-subject variability, which resulted in an inflated MS error. About halfway through testing, the latencies of the lesion group tended to stabilize, whereas the normal group's latencies displayed a continued decrease until by about Day 7 , at which time their scores dropped below that of the lesioned animals. The control group's scores remained slightly lower through the end of the testing session, adding to a significant interaction effect for Groups by Days $[\mathrm{F}(11,168)=2.44, \mathrm{p}<.05]$.

\section{DISCUSSION}

The results of this study indicate that rats with septal lesions are significantly retarded with respect to the development of positional preferences over trials. Although lesioned animals did exhibit a 


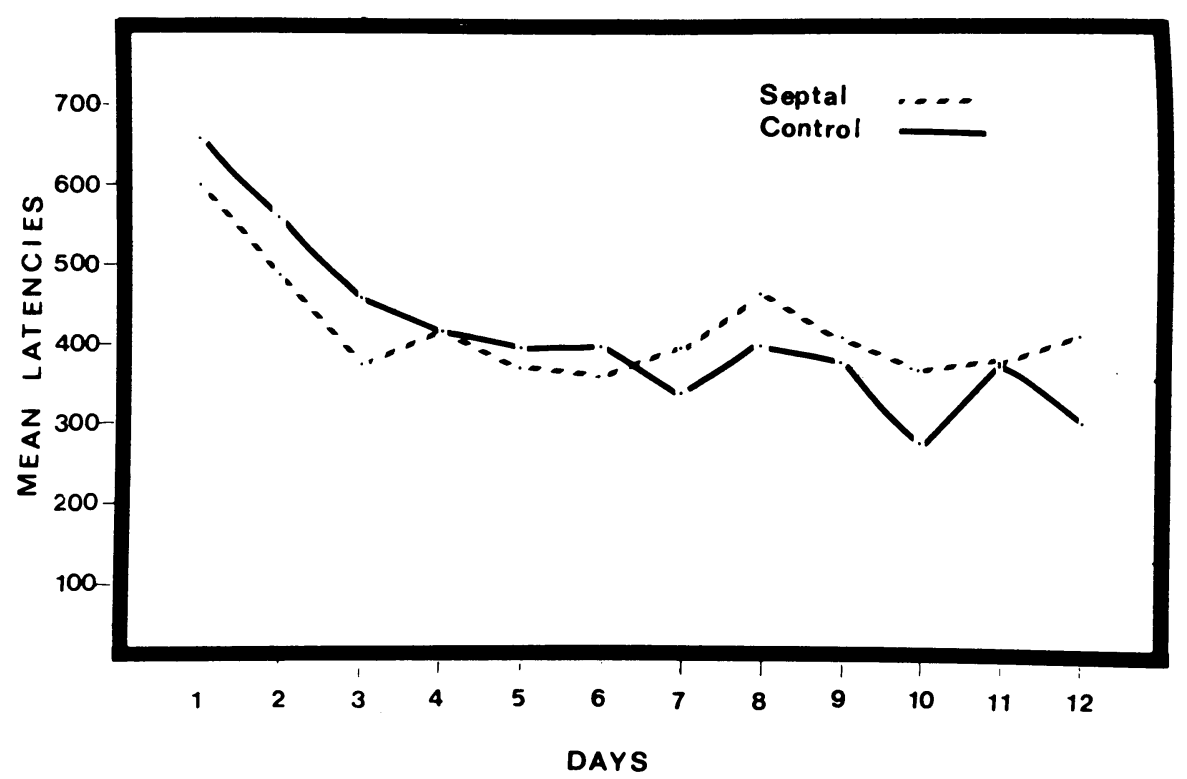

Figure 7. Mean latency over days.

relatively high initial position preference, their behavior was markedly variable throughout the first 100 trials. In contrast, control subjects were found to stabilize at the $95 \%$ level following only 50 training trials. Additionally, measures of number of choices, errors, and latency showed that lesioned animals exhibited a marked deficit on this problem even with extended practice, a finding which is in agreement with previous research, which demonstrates that septal preparations exhibit more errors than do controls on tasks which have only positional cues.

While lesioned animals exhibited a deficit on all aspects of the task, differences in time course for the preference deficit vs. the choice-error deficits would indicate that errors and positional habits are statistically independent or orthogonal. Although positional preferences improved only at the end of testing, marked improvement in errors and latency were exhibited by Group $S$ during the first 3 to 4 days. Furthermore, when predictability of the first choice preference was equal for Groups $\mathrm{S}$ and $\mathrm{N}$ (Days 11 and 12), there were still marked differences in number of choices and errors. Taken together, these results suggest that septal animals are relatively less likely to develop a strong response bias early in training, and that position preferences should interfere with acquisition of a learned task only if the task is relatively difficult or requires a large number of trials. While this interpretation is consistent with findings on difficult visual discriminations (Gomer \& Goldstein, 1974) and spontaneous alternation (Dalland, 1974; Thomas, 1972), it is in contrast with
Duncan and Duncan's (1971) findings. However, it may be that these effects do not generalize to aversively reinforced learning.

Differences in the time course for choices, errors, and position preferences also have significant ramifications for the hypothesis that lesioned animals are less able to utilize immediate information than longterm information (Stahl \& Ellen, 1973). Given that all alleys were equally correct at the beginning of a trial, errors had to occur on choices following the first in a series. Furthermore, as number of choices, errors, and latency are all interdependent (the more errors made by an animal, the more choices were recorded, and the longer the latency to finish the task), these measures can be taken as a reflection of the animals' ability to integrate information within a trial. In contrast, first-choice behaviors were independent of errors, and were separated from the last choice made by a 4-5-min intertrial interval. Interestingly, the shorter term memories (choices, errors, latency) seemed to show improvement earlier in the series than did long-term (first choice) behaviors, a finding which is in direct opposition to the hypothesis that septal lesions produce a shortterm memory deficit.

Furthermore, while septal preparations displayed a longer duration deficit on short-term measures, this deficit can be directly traced to a dissociation between Type A errors and Type B errors. The results showed that lesioned animals displayed predominantly Type A errors, partial entry into a reinforced or nonreinforced alley, whereas control subjects displayed predominantly Type B errors-full 
entry into a non-reinforced alley. Since casual observation indicated that by far the most frequent error in the septal group was partially entering an alley (Type A error), backing out, and then entering that same alley (choice response), these error scores would indicate that, if anything, lesioned animals were less likely to reenter a previously chosen goalbox, thus demonstrating that they did have some information about where they had just been.

As the preceding argument would also tend to weaken the conclusion that septal preparations are unable to utilize response-produced (spatial) information, alternative explanations of septal function must be explored. One interesting possibility is that the prevalence of Type A errors found on this task might be related to other findings which indicate that septal-damage rats exhibit more vicarious trial and error responding (Srebro, 1974) and more anticipatory errors (Kelsey \& Grossman, 1971) than do normal controls. Since this behavior also appears to be highly similar to the vacillation exhibited by normal subjects in an approach-approach task (Miller, 1951), the large number of Type A errors may indicate that septal animals are relatively unable to respond adaptively to the ambiguity associated with a task in which all goalboxes are equally likely to be reinforced, and that the presence of ambiguity (lack of discriminable cues signaling the presence of reinforcement) might be sufficient to establish the septal syndrome on this and other tasks.

\section{REFERENCES}

Butters. N. E.. \& Rosvold. H. E. Effects of caudate and septal nucleus lesions on resistance to extinction and delayed alternation. Journal of Comparative and Physiological Psychology, 1968. 65. $397-403$.

Clody. D. E..\& Carlton, P. L. Behavioral effects of lesions of the medial septum of rats. Journal of Comparative and Physiological Psychology, 1969. 67, 344-351.

Dalland. T. Stimulus perseveration of rats with septal lesions. Physiology and Behavior. 1974, 12, 1057-1061.
Douglas, R. J., \& Raphelson, A. C. Spontaneous alternation and septal lesions. Journal of Comparative and Physiological Psychology, 1966, 62. 320-322.

DeGroot, J. The rat forebrain in stereotaxic coordinates. Amsterdam: N.V. Noord-Hollandsche Vitgwers Maat Schappij, 1959.

Duncan, P. M., \& Duncan, N. C. Free operant and T-maze avoidance performance by septal and hippocampal damaged rats. Physiology and Behavior, 1971, 7, 687-693.

ElleN, P., \& ButTer, J. External cue control of DRL performance in rats with septal lesions. Physiology and Behavior, 1969, 4, 1-6.

Ellen, P., Wilson, A., \& Powell, E. Septal inhibition and tim ing behavior in the rat. Experimental Neurology, 1964, 10, 120-132.

FrIED, P. A. Pre- and post-operative approach training and conflict resolution by septal and hippocampal lesioned rats. Physiology and Behavior, 1969, 5, 975-979.

Gomer, F. E., \& Goldstein, R. Attentional rigidity during ex ploratory and simultaneous discrimination behavior in septal lesioned rats. Physiology and Behavior, 1974, 12, 19-28.

Kelsey, J. E., \& Grossman, S. P. Nonperseverative disruption of behavioral inhibition following septal lesions in rats. Journal of Comparative and Physiological Psychology, 1971, 75, 302-311.

Miller, N. E. Comments on theoretical models illustrated by the development of a theory of conflict behavior. Journal of Personality, 1951, 20, 82-100.

Schwartzbaum, J. S., \& Donovick, P. J. Discrimination reversal and spacial alternation associated with septal and caudate dysfunction in rats. Journal of Comparative and Physiological Psychology, 1968, 65. 83-92.

SinGH, D. Comparison of behavioral deficits caused by lesions in septal and ventromedial hypothalamic areas of female rats. Journal of Comparative and Physiological Psychology, 1973, 84. 370-379.

SREBro, B. Visual cues in successive position reversals: Retention deticit following septal lesions. Physiology and Behavior. 1974, 12. 639-646.

SREBro, B., \& Divac, I. Successive position reversals in rats with septal and/or fronto-polar lesions. Physiology and Behavior. 1972, 9. 269-272.

Stahl. J., \& Ellen, P. Septal lesions and reasoning performance in the rat. Journal of Comparative and Physiological Psychology, 1973, 84, 629-638.

Tномаs, J. B. Stimulus perseveration and choice behavior in rats with septal lesions. Journal of Comparative and Physiological Psychology, 1972, 80, 97-105.

(Received for publication March 24, 1977; revision accepted September 7, 1977.) 